Research Article

\title{
A prospective study, to determine adverse effects of anti-retroviral agents in rural tertiary care teaching hospital
}

\author{
Swapnil Chudaman Jaykare ${ }^{1}$, Jyoti Ramchandra Patil ${ }^{2}$, Vijay Motiram Motghare ${ }^{3}$, \\ Sudhir Laxmanrao Padwal ${ }^{4}$, Vinod Shivajirao Deshmukh ${ }^{5}$, \\ Harshal Nutanrao Pise ${ }^{4}$
}

\begin{abstract}
${ }^{1}$ Department of Pharmacology, RCSM Medical College,

Kolhapur, Maharashtra 416002, India

${ }^{2}$ Department of Pharmacology, BVDU Medical College, Sangli, Maharashtra 416414, India

${ }^{3}$ Department of Pharmacology,

GMC Nagpur, Maharashtra

440009, India

${ }^{4}$ Department of Pharmacology

SRTR GMC, Ambajogai, Dist:

Beed, Maharashtra 415417,

India

${ }^{5}$ Department of Pharmacology

GMC Latur, Maharashtra

413512, India
\end{abstract}

Received: 09 February 2016

Accepted: 14 March 2016

*Correspondence to:

Dr. Swapnil Chudaman Jaykare,

Email: swapniljaykare

@ gmail.com

Copyright: (C) the author(s), publisher and licensee Medip Academy. This is an openaccess article distributed under the terms of the Creative Commons Attribution NonCommercial License, which permits unrestricted noncommercial use, distribution, and reproduction in any medium, provided the original work is properly cited.

\begin{abstract}
Background: Acquired immunodeficiency syndrome (AIDS) is a disease of the human immune system caused by the human immunodeficiency virus (HIV). Objective of this study was to evaluate the adverse drug reaction profile of antiretroviral drugs in HIV patients in terms of causality, severity and preventability.

Methods: Patients newly started on ART were followed prospectively for a period of initial six months and were interviewed in person during their routine follow-up or visit following development of any ADRs. ADRs were screened clinically and investigated accordingly for causality, severity and preventability. Results: Out of 59 cases, zidovudine+lamivudine+nevirapine (ZLN) was the most commonly used ART regimen. A total 122 ADRs involving various systems were observed in these patients; majority being related to gastrointestinal system $(54.10 \%)$. Most of these ADRs were observed in the ZLN regimen followed by the stavudine+lamivudine+nevirapine (SLN) regimen. On causality assessment in ZLN regimen, $74.58 \%$ of ADRs were possible, while $25.42 \%$ were probable. Severity assessment showed that most of the ADR were mild whereas on preventability assessment it was observed that most of the ADRs were not-preventable.

Conclusions: Antiretroviral drugs are not solely responsible for the ADRs due to these medications; various co-morbid and predisposing conditions share the responsibility. An efficient pharmacovigilance is imperative by means of improving ADR reporting and monitoring, in order to improve compliance and acceptability of ART.
\end{abstract}

Keywords: ADRs, AIDS, Antiretroviral therapy, Causality, Pharmacovigilance, Preventability, Severity

\section{INTRODUCTION}

Acquired immunodeficiency syndrome (AIDS) is a disease of the human immune system caused by the human immunodeficiency virus (HIV). ${ }^{1}$ AIDS is a major health problem in many parts of the world, and is considered as a pandemic disease outbreak. ${ }^{2}$ In 2009 , the world health organization (WHO) estimated that there are 33.4 million people worldwide living with HIV/AIDS, with 2.7 million new HIV infections per year and 2.0 million annual deaths due to AIDS. ${ }^{3}$

Although treatments for HIV/AIDS can slow the course of the disease, there is no known cure or vaccine for HIV. 
Antiretroviral therapy (ART) reduces both the deaths and new infections from HIV/AIDS, but these drugs are expensive and they are associated with well-known side effects and adverse drug reactions (ADRs). ${ }^{4}$ Unfortunately, adverse effects of these drugs are of serious concern. Adverse reactions to antiretroviral drugs in HIV patients cause medication non-adherence leading to treatment failure.

The national pharmacovigilance programme of India lack continuity. There is a lack of awareness and inadequate training about drug safety monitoring among healthcare professionals in India. Often ADRs go unnoticed or are not reported. In India, very few studies have been conducted concerning ADRs in HIV patients receiving ART in rural set up. Hence the present study was proposed to evaluate the adverse drug reaction profile of anti-retroviral agents in HIV patients with the objectives to assess causality, severity and preventability of ADRs due to anti-retroviral agents in HIV patients.

\section{METHODS}

It was prospective, observational study conducted after obtaining approval from the institutional ethics committee (IEC). Study population was all HIV/ AIDS diagnosed patients presenting to ART centre of our hospital. Subjects were selected from study population based on inclusion criteria and exclusion criteria.

\section{Inclusion criteria}

New cases, both males and females receiving ART in age group of 18-60 years.

\section{Exclusion criteria}

Patients not willing to participate in the study. Patients with age $<18$ years and age $>60$ year. Pregnant and lactating patients.
Subjects were recruited for a period of two months and were followed up for the period of six months from commencement of ART after obtaining written informed consent from the patients. Data were collected with the help of a specially designed case record form. Data collected was

- Baseline investigation ( $\mathrm{Hb} \%, \mathrm{CBC}, \mathrm{CD} 4$ count, LFT, RFT, CXR, HbsAg, VDRL, USG abdomen)

- Current treatment regimen

- Concomitant drugs prescribed

- Co-infections

- Adverse drug reaction if any type, nature, severity, management

Confidentiality about patient's identity was maintained throughout the study. Causality assessment was done using naranjo's causality algorithm, Severity assessment was done using modified hartwig siegel's scale and preventability assessment was done using schumock and thornton criteria. Data obtained was analysed using descriptive statistics. ${ }^{6-8}$

\section{RESULTS}

Total numbers of 62 patients were included in the study and were followed for a period of six months. Amongst these, three patients were lost to follow-up. In the present study (Table 1), 54.24\% cases were female and $45.76 \%$ were males. Most (74.58\%) of these cases were from 26 to 45 years age group. It was observed that the literacy rate was quite low $(42.37 \%)$ with $57.63 \%$ of the population being illiterate. The unemployment rate was $62.71 \%$, while only $37.29 \%$ were employed.

Table 1: Demographic details.

\begin{tabular}{|llllllllll|}
\hline & \multicolumn{3}{c}{ Gender } & \multicolumn{3}{c}{ Age } & \multicolumn{2}{c}{ Literacy } & \multicolumn{2}{c|}{ Employment } \\
& M & F & $<\mathbf{2 5}$ & $\mathbf{2 6 - 4 5}$ & $\mathbf{> 4 6}$ & Literate & Illiterate & Employed & Unemployed \\
\hline No. of patients \% & 45.76 & 54.24 & 8.47 & 74.58 & 16.95 & 42.37 & 57.63 & 37.29 & 62.71 \\
\hline
\end{tabular}

Table 2: Patient distribution in various ART regimens.

\begin{tabular}{|ll|}
\hline ART Regimen & No. of Patients (\%) \\
\hline Zidovudine+lamivudine+nevirapine & 38.98 \\
\hline Stavudine+lamivudine+nevirapine & 35.59 \\
\hline Zidovudine+lamivudine+efavirenz & 18.64 \\
\hline Stavudine+lamivudine+efavirenz & 6.79 \\
\hline
\end{tabular}

Table 3: Clinical stage-wise patient distribution.

\begin{tabular}{|lc|}
\hline WHO clinical stage & No. of patients $(\%)$ \\
\hline Clinical stage I & 8.33 \\
\hline Clinical stage II & 56.67 \\
\hline Clinical stage III & 25 \\
\hline Clinical stage IV & 10 \\
\hline
\end{tabular}


Table 4: Systemic classification of adverse drug reactions.

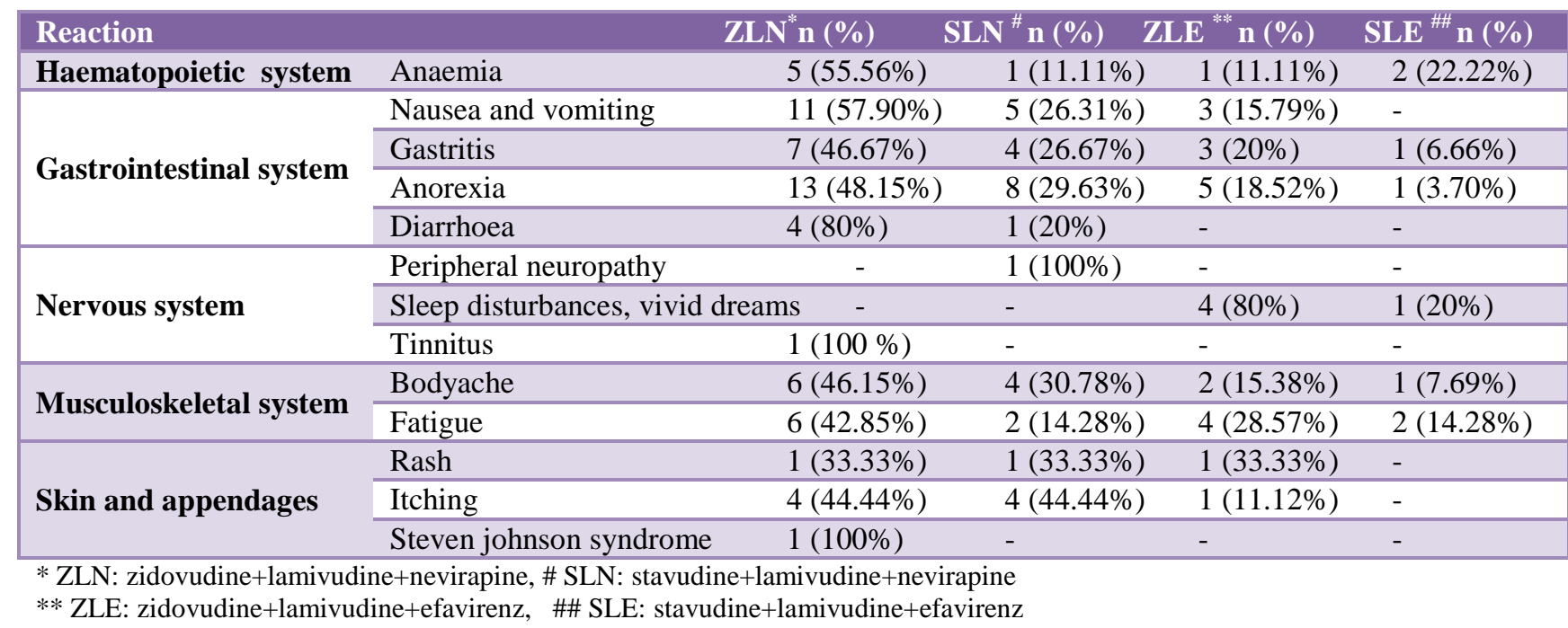

Table 5: Adverse drug reaction to ART and causality.

\begin{tabular}{|lllll|}
\hline ART Regimen & \multicolumn{4}{c|}{ Causality assessment of ADR (\%) } \\
\hline Zidovudine+lamivudine+nevirapine & Definite & Probable & Possible & Doubtful \\
\hline Stavudine+lamivudine+nevirapine & - & 25.42 & 74.58 & - \\
\hline Zidovudine+lamivudine+efavirenz & - & 19.35 & 80.65 & - \\
\hline Stavudine+lamivudine+efavirenz & - & 20.83 & 79.17 & - \\
\hline
\end{tabular}

Table 6: Adverse drug reaction to ART and severity.

\begin{tabular}{|lllll|}
\hline ART Regimen & \multicolumn{3}{c|}{ Severity assessment of ADR (\%) } \\
\hline Zidovudine+lamivudine+nevirapine & Mild & Moderate & Severe & Lethal \\
\hline Stavudine+lamivudine+nevirapine & 77.98 & 16.94 & 5.08 & 0.00 \\
\hline Zidovudine+lamivudine+efavirenz & 90.34 & 6.44 & 3.22 & 0.00 \\
\hline Stavudine+lamivudine+efavirenz & 79.18 & 16.66 & 4.16 & 0.00 \\
\hline
\end{tabular}

As shown in (Table 2) patients received four treatment regimens as per NACO guidelines. Amongst them zidovudine+lamivudine+nevirapine was the most commonly used regimen (in $38.98 \%$ of the patients) followed by stavudine+lamivudine+nevirapine (in 35.59 $\%$ of the patients) while the least number of patients received stavudine+lamivudine+efavirenz regimen $(6.79 \%)$.
At the initiation of therapy most of the patients (55.93\%) were under WHO clinical stage II. During the follow-up, it was observed that few patients who were initially in stage III, having received ART, showed clinical improvement and were later categorised under stage II.

Table 7: Adverse drug reaction to ART and preventability.

\begin{tabular}{|lll|}
\hline ART Regimen & \multicolumn{2}{c|}{ Preventability assessment of ADR (\%) } \\
\hline Zidovudine+lamivudine+nevirapine & Preventable & Not preventable \\
\hline Stavudine+lamivudine+nevirapine & 27.12 & 72.88 \\
\hline Zidovudine+lamivudine+efavirenz & 9.68 & 90.32 \\
\hline Stavudine+lamivudine+efavirenz & 16.67 & 83.33 \\
\hline
\end{tabular}


Adverse drug reactions were reported in 32 (54.24\%) patients out of the 59 patients recruited in the study (Table 4). A total number of 122 ADRs involving various systems were observed in these patients. Incidence of gastrointestinal system related ADRs were high 66 $(54.10 \%)$ in majority of the cases followed by musculoskeletal system $27(22.11 \%)$. The other systems involved were nervous system 7 (5.74\%), Haematopoietic system $9(7.38 \%)$ and skin and appendages $13(10.65 \%)$. Most of these ADRs were observed in the ZLN regimen followed by the SLN regimen, as described in (Table 4). The incidence of ADRs was lowest in the SLE regimen which could be attributed to the fact that only a few patients received this regimen.

When causality assessment was done as per Naranjo's causality algorithm (Table 5), it was observed that in ZLN regimen, $25.42 \%$ of ADRs were probable, while $74.58 \%$ ADRs were possible. Similarly, as shown in table 5 the causality assessment of other regimens revealed that most of the reactions were possible, followed by probable and none of the reactions were definite or doubtful.

The severity assessment (Table 6), carried out as per modified hartwig siegel's scale, showed that majority of the reactions were mild in almost all the patients with complete recovery without requiring any change in regimen. Very few ADRs were severe enough to necessitate the switchover to other regimen. Nevirapine induced steven johnson syndrome was observed in one patient receiving the ZLN regimen. This patient was hospitalised, dechallenged and switched over to other regimen. Patient showed complete recovery after the treatment. One patient receiving stavudine based therapy developed peripheral neuropathy necessitating change of his regimen. Few reactions were moderate in nature so, were managed by symptomatic treatment alone without changing the regimens.

Preventability assessment of ADRs (Table 7), carried out as per the schumock thornton's criteria showed that ADRs were not-preventable in most of the cases in all the treatment regimens.

\section{DISCUSSION}

Adverse drug reaction is response to a drug which is noxious and unintended, which occurs at doses normally used in humans for prophylaxis, diagnosis, therapy of disease or the modification of the physiological function. ${ }^{9}$ The term side effects is frequently used in practice to describe the adverse drug reactions, however, it comes under the umbrella of the latter. Adverse drug reactions include side effects, allergies and hypersensitivity reactions. However, drug withdrawal, drug abuse syndromes, accidental poisoning and drug-overdose related complications should not be confused with ADRs.

The adverse drug reactions to the drugs are the major cause of non-compliance to anti-retroviral therapy. Hence, in order to prevent the occurrence of severe ADRs and improve the compliance, close monitoring of the patients on ART is important. ART has wide range of adverse effects on human body. ${ }^{10}$ These manifestations range from mild to severe reactions. The commonly observed mild reactions are related to the gastrointestinal system such as nausea, anorexia, vomiting and epigastric burning. ${ }^{11}$ Other common ADRs are fatigue, headache, sleep disturbances and peripheral neuropathy. These reactions are attributed to the individual drugs in the ART regimens. Sometimes, severe reactions like lactic acidosis, hepatotoxicity, osteoporosis, skin rash and metabolic disturbances such as hyperglycaemia and hyperlipidemia, are also seen following the long term use of these drugs. ${ }^{10}$

The incidence of ADRs to ART is higher during the initial few months after its commencement. ${ }^{12}$ In our study, we have focussed on the adverse drug reactions occurring in these patients during the first six months following the commencement of ART.

Earlier in our country, there was a greater prevalence of HIV amongst the female patients, but the 2010-11 annual report by NACO suggests that this prevalence is declining recently. ${ }^{13}$ However, the demographic data of our study, suggests the preponderance of female patients especially in the age group, 26-45 years. Majority (55.93\%) of the patients were in WHO clinical stage II at the initiation of the treatment. However after receiving ART for 3-4 months, few patients from stage III showed improvement and were shifted to stage II.

In the present study, 122 ADRs were observed in 59 patients with a prevalence of $196.78 \%$ which is much higher than that reported by Modayil RR et al (17.5\%) 14 and comparable with that reported by Nagpal $\mathrm{M}$ et al $(263 \%){ }^{15}$ The common ADRs were related to the gastrointestinal system $(54.10 \%)$. The previous studies also showed similar results. Sharma A et al reported $10 \%$ incidence of gastrointestinal ADRs while O'Brien ME et al suggested that it was the most common (4.4\%) cause for non-adherence to ART. ${ }^{16,17}$

One patient receiving nevirapine developed skin rash and was diagnosed as a case of steven johnson syndrome. This ADR was reported to uppsala monitoring centre, Sweden. Various case reports of nevirapine induced steven johnson syndrome have been reported in recent few years. ${ }^{18}$ Peripheral neuropathy was observed exclusively in the stavudine-based regimen whereas that of anaemia was significantly high $(55.56 \%)$ in the zidovudine-based regimen. This is similar to the findings of the study conducted by Modayil RR et al and Eluwa GI et al respectively. ${ }^{14,19}$ One of the patient receiving zidovudine based regimen developed severe pancytopenia following which he was managed aggressively and was switched over to non-zidovudine based regimen. Various other documented reactions were also seen but they were less frequent and were not severe enough warranting substitution of the regimen, suggesting better tolerability of ART.

The Pharmacovigilance profile of all these ADRs revealed that on causality assessment, most of them were possible in nature followed by probable. This could be attributed to 
the fact that rechallenge could not be performed in the patients. Severity assessment showed that most of the ADRs were mild in nature suggesting better tolerability to ART which might explain the good compliance observed in our study. The occurrence of severe ADRs in very few patients could be because of concomitant administration of Anti-tubercular drugs or other comorbid conditions. Higher prevalence of non-preventable ADRs demands strict vigilance to the ADR monitoring to ensure better patient care and compliance. Strategies should be developed and implemented which will make ART more acceptable and tolerable.

\section{CONCLUSION}

ART plays a major role in improving the quality of life of HIV infected individuals. Antiretroviral drugs are not solely responsible for the ADRs occurring in the patients on these medications; various co-morbid and predisposing conditions simulate the clinical scenario. An efficient pharmacovigilance is imperative by means of improving ADR reporting and monitoring right from the time of initiation of these drugs. On the basis of the data generated by the on-going pharmacovigilance program, strategies should be designed and implemented to ensure the compliance and acceptability of ART and other therapies.

\section{Funding: No funding sources}

Conflict of interest: None declared

Ethical approval: The study was approved by the Institutional Ethics Committee

\section{REFERENCES}

1. Weiss RA. How does HIV cause AIDS? Science 1993;260:1273-79.

2. Kallings LO. The first postmodern pandemic: 25 years of HIV/ AIDS. J Intern Med. 2008;263:218-43.

3. Jacob IS, Singh A, Suryawanshi SN, Gautam V. Insilico inhibitor designing for $\mathrm{HIV}-1$ integrase in human immunodeficiency virus. J Nat Sc Biol Med. 2011;2:64-5.

4. Jaykare SC, Motghare VM, Padwal SL, Pise HN, Deshpande RP. Antiretroviral therapy- newer drugs on the anvil. Indian Journal of Medical Specialities. 2013;4:47-54.

5. Cooper CL, Breau C, Laroche A, Lee C, Garber G. Clinical outcomes of first antiretroviral regimen in HIV/hepatitis C virus co-infection. HIV Med. 2006;7:32-7.

6. Naranjo C, Busto U, Sellers E, Sandor P, Ruiz I, Roberts E, et al. A method for estimating the probability of adverse drug reactions. Clin Pharmacol Ther. 1981;30:239-45.

7. Hartwig S, Siegel J, Schneider P. Preventability and severity assessment in reporting adverse drug reactions. Am J Hosp Pharm. 1992;49:2229-32.

8. Schumock GT, Thornton JP. Focusing on the preventability of adverse drug reactions. Hosp Pharm.1992;27:538.

9. American society of health-system pharmacists. ASHP guidelines on adverse drug reaction monitoring and reporting. Am J Health-Syst Pharm. 1995;52:417-9.

10. Montessori V, Press N, Harris M, Akagi L, Montaner JS. Adverse effects of antiretroviral therapy for HIV infection. CMAJ. 2004;170:229-38.

11. Carr A, Cooper DA. Adverse effects of antiretroviral therapy. Lancet. 2000;356:1423-30.

12. Duval X, Journot V, Leport C, Chene G, Dupon M, Cuzin L, et al. Incidence of and risk factors for adverse drug reactions in a prospective cohort of HIV-infected adults initiating protease inhibitorcontaining therapy. Clin Infect Dis. 2004;39:248-55.

13. Annual Report 2010-11. National aids control organization. Available at http://www.nacoonline.org/upload/REPORTS/NACO \%20Annual\%20Report\%202010-11.pdf.

14. Modayil RR, Harugeri A, Parthasarathi G, Ramesh M, Prasad R, Naik V, et al. Adverse drug reactions to antiretroviral therapy (ART): an experience of spontaneous reporting and intensive monitoring from ART centre in India. Pharmacoepidemiol Drug Saf. 2010;19:247-55.

15. Nagpal M, Tayal V, Kumar S, Gupta U. Adverse drug reactions to antiretroviral therapy in AIDS patients at a tertiary care hospital in India: A prospective observational study. Indian $\mathrm{J}$ Med Sci. 2010;64:245-52.

16. Sharma A, Vora R, Modi M, Sharma A, Marfatia Y. Adverse effects of antiretroviral treatment. Indian $\mathbf{J}$ Dermatol Venereol Leprol. 2008;74:234-7.

17. O’Brien ME, Clark RA, Besch CL, Myers L, Kissinger P. Patterns and correlates of discontinuation of the initial HAART regimen in an urban outpatient cohort. J Acquir Immune Defic Syndr. 2003;34:407-14.

18. Singh H, Kachhap VK, Kumar BN, Nayak K. Nevirapine induced stevens-johnson syndrome in an HIV infected patient. Indian $\mathbf{J}$ Pharmacol. 2011;43:84-6.

19. Eluwa GI, Badru T, Akpoigbe K. Adverse drug reactions to antiretroviral therapy (ARVs): incidence, type and risk factors in Nigeria. BMC Clinical Pharmacology. 2012;12:7.

Cite this article as: Jaykare SC, Patil JR, Motghare VM, Padwal SL, Deshmukh VS, Pise HN. A prospective study, to determine adverse effects of anti-retroviral agents in rural tertiary care teaching hospital. Int J Basic Clin Pharmacol 2016;5:713-7. 